\title{
Evidence-Experience Gap and Future Perspective on the Treatment of Peripheral Artery Disease
}

\author{
Osamu lida ${ }^{1}$, Mitsuyoshi Takahara ${ }^{2}$ and Toshiaki Mano ${ }^{1}$ \\ ${ }^{1}$ Cardiovascular Center, Kansai Rosai Hospital, Hyogo, Japan \\ ${ }^{2}$ Department of Diabetes Care Medicine, Osaka University Graduate School of Medicine, Osaka, Japan
}

Peripheral artery disease (PAD) is a systemic disease associated with impaired limb function, poor quality of life, and increased cardiovascular morbidity. Its incidence has been dramatically increasing over years because of the emergence of an aging society and the increase in the number of patients with atherosclerotic risk factors. The clustering of these risk factors promotes disease development, reportedly leading to the differential location of atherosclerotic lesions in lower extremity arteries. The clinical presentations of PAD include intermittent claudication and chronic limb-threatening ischemia (CLTI). PAD is associated with a high risk of mortality and morbidity from both cardiovascular and limb events. The therapeutic goals for patients with PAD include 1) relief from PAD-related limb symptoms, 2) the prevention of new-onset and the development and recurrence of $\mathrm{PAD}$, and 3) the prevention of concomitant adverse events due to coronary artery disease (CAD) and cerebrovascular disease (CVD). There are several types of antithrombotic agents, and their main role in patients with PAD is to reduce systemic events mainly including cardiovascular and lower extremity-related events. Currently, the efficacy of direct oral anticoagulant (DOAC) is also suggested by recent clinical trials. Although endovascular therapy (EVT) has been a first-line revascularization strategy for symptomatic PAD, whether clinical outcomes after EVT are comparable to those after surgical bypass therapy remains inconclusive.

Key words: Peripheral artery disease, Chronic limb-threatening ischemia, Endovasular therapy

\section{Clinical Features of Peripheral Artery Disease in Japanese Patients}

Peripheral artery disease (PAD) is currently the third leading cause of atherosclerotic cardiovascular morbidity, following coronary artery disease (CAD) and cerebrovascular disease $(\mathrm{CVD})^{1,2)}$. Its incidence has been increasing over years because of the emergence of an aging society and the increase in the number of patients with atherosclerotic risk factors, including diabetes mellitus (DM), dyslipidemia, and renal insufficiency ${ }^{3-5)}$. A previous systematic review reported that the number of individuals with PAD increased by $28.7 \%$ in low- or middle-income countries and by $13.1 \%$ in high-income countries during the last decade, revealing that PAD has become a global issue in the 21 st century ${ }^{6}$.
The clustering of cardiovascular risk factors promotes the disease development. A recent metaanalysis showed a progression to worsening intermittent claudication or chronic limb-threatening ischemia (CLTI) in 21\% (12\%-29\%) over 5 years ${ }^{7)}$. A comparison of the characteristics of Japanese and nonJapanese patients with PAD with claudication who underwent drug-coated stent (DCS) therapy revealed that body mass index was lower in Japanese patients than in non-Japanese patients and that dyslipidemia was less frequently observed in Japanese patients than in non-Japanese patients ${ }^{8)}$. The clinical characteristics of Japanese patients with CLTI are also substantially different from those of non-Japanese patients. DM, renal insufficiency including hemodialysis (HD), and tissue loss are more frequently observed in Japanese patients with CLTI than in non-Japanese patients with

Address for correspondence: Osamu lida, Kansai Rosai Hospital, Cardiovascular Center, 3-1-69 Inabaso, Amagasaki, Hyogo 660-8511, Japan

E-mail: iida.osa@gmail.com

Received: April 30, 2021 Accepted for publication: May 4, 2021

Copyright@2021 Japan Atherosclerosis Society

This article is distributed under the terms of the latest version of CC BY-NC-SA defined by the Creative Commons Attribution License. 
CLTI $^{9-14)}$. Notably, patients with CLTI who underwent HD account for about half of all CLTI cases in Japan, which is one of the major characteristics of CLTI in Japan ${ }^{9,12)}$. This may be related to the fact that Japan has a lower kidney transplantation rate than other countries, although Japan has a universal health insurance system that allows the initiation of dialysis in all cases resulting in end-stage renal failure, regardless of age ${ }^{15}$. Patients with PAD in Japan are characterized by older age, a lower body weight, a lower prevalence of dyslipidemia, and a higher prevalence of DM and HD compared with those in Europe and North America. Accordingly, the features of symptomatic PAD are different between Japan and other countries.

The location of lesions in lower extremity arteries varies according to accumulating atherosclerotic risk factors. Dyslipidemia and smoking are more likely to cause atherosclerotic lesions in the proximal inflow region, whereas age, DM, and renal failure are significantly associated with lesions in the distal outflow region. In particular, as renal function worsens, the incidence of below-the-knee (BTK) arterial disease increases ${ }^{16}$. More peripheral, distal lesions often increase the difficulty of both endovascular and surgical revascularization procedures. Therefore, it is no exaggeration to say that there are a substantial number of PAD cases in Japan that are the most challenging to treat in the world.

In patients with PAD, a clinical assessment of symptoms and physical signs of other atherosclerotic diseases, including CAD, is mandatory, and in cases of clinical suspicion, further tests will be needed. In patients with PAD, $25 \%-70 \%$ of cases have concomitant $\mathrm{CAD}^{17,18)}$. The severity and complexity of CAD specifically evaluated with the SYNTAX score $^{19)}$ are higher in patients with CLTI than in those with claudication ${ }^{20)}$. A higher score would be attributed to a higher prevalence of older age, DM, and renal insufficiency in patients with CLTI. Although there is no doubt that the presence of CAD in PAD adversely impacts clinical outcomes compared with the absence of CAD in $\mathrm{PAD}^{18)}$, previous studies demonstrated that the prognostic impact of the presence of CAD and reduced cardiac contraction appears different between patients with IC (Intermittent claudication) and CLTI ${ }^{19)}$. The latest European Society of Cardiology (ESC)/European Society for Vascular Surgery (ESVS) 2017 guideline newly recommends screening for presence of heart failure with transthoracic echocardiography and/or natriuretic peptide assessment in patients with symptomatic PADs under class IIa and level C recommendation ${ }^{17)}$.

\section{Clinical Issues of Japanese Patients with CLTI before Revascularization Approach}

The natural course of CLTI without undergoing appropriate intervention is dire, with a high risk for major amputation. Therefore, revascularization should be considered as the first-line therapy for patients with CLTI ${ }^{17,21)}$. There have been several discussions about the decision-making of which revascularization strategies should be selected, either endovascular or surgical revascularization. However, we believe that there are larger issues before referral to vascular specialists.

As stated in the TransAtlantic Inter-Society Consensus (TASC) II guidelines ${ }^{22)}$, about half of the patients who underwent major BTK or above-theknee amputations for PAD were asymptomatic 6 months before. In general, some may assume a gradual progression from minor (asymptomatic) to severe (CLTI) symptoms via "moderate" symptoms (claudication); however, CLTI can be developed from asymptomatic status without any claudication. In the SPINACH (Surgical Reconstruction Versus Peripheral Intervention in Patients With Critical Limb Ischemia) study, including both patients with CLTI undergoing surgical bypass therapy and those with endovascular therapy (EVT) in Japan ${ }^{9)}$, history of intermittent claudication before the onset of CLTI was surveyed. Surprisingly, about half of the patients had no history of intermittent claudication ${ }^{23)}$. The risk factors for the lack of claudication history were the presence of DM, HD, and nonambulatory status ${ }^{23)}$. Based on this result, if patients have no symptom but with these risk factors, including $\mathrm{DM}, \mathrm{HD}$, and nonambulatory status, careful follow-up would be needed with awareness of their high risk of subsequent occurrence of CLTI. The SPINACH study also surveyed the duration between the occurrence of wound and reference to a vascular center. Unexpectedly, wound duration exceeded 1 month in $60 \%$ of patients and 3 months (i.e., one season) in $17 \%{ }^{23)}$. No clinical features were significantly associated with wound duration. Wound duration was independently associated with wound severity evaluated using the Wound, Ischemia, and Foot Infection classification system ${ }^{24)}$. A substantial number of patients with CLTI referred to vascular centers had a long wound duration, and these results suggest that a smoother referral process would enable the initiation of optimal treatment before the worsening of the ischemic wound.

\section{Medical Intervention}

The therapeutic goals for patients with PAD 
include 1) relief from PAD-related symptoms, 2) the prevention of new-onset and the development and recurrence of PAD, and 3) the prevention of concomitant adverse events due to CAD and CVD (myocardial infarction and stroke) ${ }^{21)}$. The management of each atherosclerotic risk factor would have an impact on new-onset and the development and recurrence of PAD. Recent guidelines recommend that blood pressure be controlled to less than 140/90 $\mathrm{mmHg}$ (less than $130 / 80 \mathrm{mmHg}$ in patients with $\mathrm{DM}{ }^{25-28)}$. ACE inhibitors are firstly recommended as antihypertensive drugs, whereas $\beta$-blockers are also effective in lowering blood pressure without worsening symptoms ${ }^{17)}$. The latest ESC 2019 guideline also recommends that LDL cholesterol be controlled to less than $55 \mathrm{mg} / \mathrm{dL}$ in patients with $\mathrm{PAD}^{29)}$. In patients with DM, maintaining a glycosylated hemoglobin A1c level of $<7 \%$ is often recommended ${ }^{30-33)}$; however, less stringent goals (e.g., hemoglobin A1c level of $<$ $8 \%$ ) may be appropriate for individuals with advanced vascular complications or limited life expectancy ${ }^{34)}$. Several studies demonstrated that antithrombotic therapy plays a major role in the prevention of concomitant adverse events due to CVD and the reduction of recurrence after revascularization (EVT/ surgical therapy) ${ }^{35-37)}$. Paradoxically, despite the robust recommendation of medical intervention for patients with $\mathrm{PAD}$, the rate of optimal medical therapy (OMT) treatment (statin + RA antihypertensive + antiplatelet agent) recommended here is clearly lower in patients with PAD than in patients with CVD and $\mathrm{CAD}^{38)}$, and it has been reported that OMT is not sufficiently implemented. The suboptimal prescription of these guideline-direct medical therapies in patients with PAD is associated with multiple factors, including female sex ${ }^{39)}$.

Since the mechanism of event occurrence is different among cardiovascular and limb-related events, understanding antithrombotic agents with different efficacies is needed; however, their specific indications remain unclear. Two placebo-controlled randomized trials in asymptomatic patients with PAD demonstrated that a single antiplatelet therapy had no beneficial effect in reducing ischemic cardiovascular and limb-related events ${ }^{40,41}$. On the other hands, in patients with symptomatic PAD, the strongest evidence on secondary prevention in favor of aspirin to protect against major cardiovascular events (MACE) was reported ${ }^{42)}$. The Clopidogrel versus Aspirin in Patients at Risk of Ischaemic Events trial demonstrated that clopidogrel was superior to aspirin in a subgroup of patients with $\mathrm{PAD}$, with significant reductions in cardiovascular mortality and MACE, without any increasing risk of bleeding events ${ }^{35}$. To date, the superiority of dual antiplatelet therapy (DAPT) to single antiplatelet therapy in cardiovascular risk reduction in patients with PAD has not been proved. The Clopidogrel for High Atherothrombotic Risk and Ischemic Stabilization, Management, Avoidance trial demonstrated that DAPT with clopidogrel plus aspirin versus aspirin alone did not reduce MACE ${ }^{43)}$. Observational studies on antithrombotic therapies in real-world populations have demonstrated an association between DAPT and a lower risk of MACE and mortality in symptomatic PAD compared with aspirin monotherapy ${ }^{44)}$. DAPT is currently considered for patients undergoing EVT for coronary intervention. DAPT is generally recommended for at least 1 month after EVT, irrespective of the device type (bare-metal stent and drug-eluting stent $(\mathrm{DES}))^{17)}$. In the Zilver PTX trial comparing provisional DCS to bare-metal stents, DAPT was mandated for 2 months ${ }^{8}$. In the IMPERIAL (ELUVIA $^{\text {TM }}$ Drug-eluting Stent Versus Zilver ${ }^{\circledR}$ PTX® Stent) randomized trial comparing Zilver PTX versus Eluvia DES, DAPT was again mandated for 2 months $s^{45)}$. In the treatment of angioplasty with or without drug coating, at least 1 -month DAPT is mandated for preventing risk of acute occlusion and thereafter can be switched to single antiplatelet therapy, which is its main advantage as an endovascular device. However, in real-world practice, the duration of DAPT is individually determined by procedural complexity. Long stenting is often followed by a longer period of DAPT, but no specific evidence is available. In the field of surgical bypass therapy, the Clopidogrel and Acetylsalicylic Acid in Bypass Surgery for Peripheral Arterial Disease study demonstrated that DAPT therapy compared with SAPT (single antiplatelet therapy) therapy after surgical peripheral revascularization had no beneficial effect on the composite of graft occlusion, revascularization, amputation, or death and significantly increased the risk of moderate or severe bleeding ${ }^{37)}$. Anticoagulation has been prospectively tested after surgical and endovascular intervention for symptomatic PAD. The VOYGER-PAD (Vascular Outcomes Study of ASA Along With Rivaroxaban in Endovascular or Surgical Limb Revascularization for Peripheral Artery Disease) trial evaluated whether additional DOAC would reduce cardiovascular and limb-related events after endovascular or surgical treatment. Approximately, two-thirds of patients were endovascularly treated, whereas the reaming one-third was surgically treated. The clinical presentations were claudication and CLTI in $77 \%$ and $23 \%$, respectively. Compared with aspirin alone, additional low-dose rivaroxaban significantly reduced the composite endpoint of lower extremity 
(acute limb ischemia and major amputation of the lower extremity) and systemic (myocardial infarction, ischemic stroke, and cardiovascular death) events ${ }^{46)}$. In particular, acute arterial occlusion was significantly reduced. Previously, the VANQUISH (Viabahn StentGraft Placement for Femoropopliteal Diseases Requiring Endovascular Therapy) study evaluated the relationship between vessel patency and P2Y12 reaction unit (PRU) values, a marker of the resistance on P2Y12 inhibition (antiplatelet effect), after the stent-grafting of patients with symptomatic PAD presenting femoropopliteal artery lesions. The study found no relationship between PRU values and vessel patency ${ }^{47)}$, suggesting that the effect of antiplatelet therapy would have a small, if any, influence on vessel patency. Clinical attention is shifting from the intensification of antiplatelet therapy to the introduction of DOACs. Antithrombotic drug selection is mainly determined by the condition of each patient with PAD. In the short to intermediate term after revascularization, major adverse limb event (MALE) more commonly occurred than MACE, and the risk should be more cautiously followed. In the long-term, the risk of MALE would be attenuated, but patients would be subject to a continuous risk of MACE. Antiplatelet therapy selection should be driven by the tradeoff of ischemic and bleeding risks in patients with PAD as a chronic atherosclerotic disease.

\section{When and How to Consider Revascularization for Patients with PAD}

1) Indication of Revascularization in Patients with PAD

Patients with intermittent claudication will be an absolute indication for revascularization only when the symptom is refractory to pharmacotherapy and exercise therapy. In contrast, revascularization is the first-line treatment in patients with CLTI for their limb salvage ${ }^{17,21,22)}$. In principle, asymptomatic patients should not be indicated for revascularization. However, in clinical practice, to date, either endovascular or surgical intervention is allowed in patients with anastomotic stenosis after surgical bypass therapy, even if they are asymptomatic ${ }^{21}$. A recent clinical study reported that planned-EVT, i.e., performing TLR every two months regardless of SPP values until complete wound healing was obtained, shortened the time to wound healing in patients undergoing BTK-EVT for CLTI presenting tissue loss ${ }^{48)}$. Reintervention has been generally indicated for recurrent symptom or delayed wound healing accompanied by the "presence of restenosis with hemodynamically changes." Planned-EVT strategy is a novel approach that would potentially improve clinical outcomes.

\section{2) Stratification of Anatomical Severity in Patients with PAD}

The classification of anatomical severity in patients with $\mathrm{PAD}$ plays an important role in the selection of revascularization methods. It has been categorized based on the expected technical success and long-term patency of EVT. Until now, the TASC 2000 and TASC II classifications have been commonly used to evaluate the severity of the disease ${ }^{22,}{ }^{49}$; however, the ESC/ESVS 2017 no longer described the TASC-based selection of revascularization methods ${ }^{17)}$. More recently, the global vascular guideline (GVG), specialized for the treatment of CLTI, proposed the GLASS classification by simultaneously evaluating the femoropopliteal and infrapopliteal arterial segments ${ }^{17}$.

In aortoiliac lesions, the TASC II classification is somewhat complicated and is not always easy to use in clinical practice. The Observational Prospective Multicenter Registry Study on Outcomes of Peripheral Arterial Disease Patients Treated by Angioplasty Therapy for Aortoiliac Artery registry, which was conducted at 64 centers in Japan to clarify the clinical outcomes of aortoiliac EVT in real-world practice, showed that the presence of concomitant femoropopliteal lesion and minimum stent diameter were significantly associated with 1-year restenosis, whereas the TASC II classification was not ${ }^{50)}$. In femoropopliteal lesions, the TASC II classification mainly stratified lesions by their length and the presence of chronic total occlusion (CTO); however, previous studies have shown that anatomical characteristics other than lesion length and CTO were significantly associated with loss of patency. The IntraVascular UltrasOundSuppoRted Endovascular Therapy in Superficial Femoral ArterY Disease Prospective multicenter registry study proposed a novel angiographic risk score consisting of distal reference vessel diameter, lesion length, and CTO, which is significantly and independently associated with the 12 -month restenosis risk after EVT ${ }^{51)}$. Regarding BTK and below-theankle (BTA) lesions, a single-center, retrospective study showed that BTK arterial calcification and poor BTA runoff were significantly associated with delayed wound healing, whereas the GLASS classification was not $^{52)}$. Further investigation will be needed to validate GLASS predicting clinical outcomes.

3) Revascularization Strategy (Surgical or Endovascular Approach)

\section{Revascularization for Aortoiliac Lesions}

According to the ESC/ESVS 2017 guidelines, 


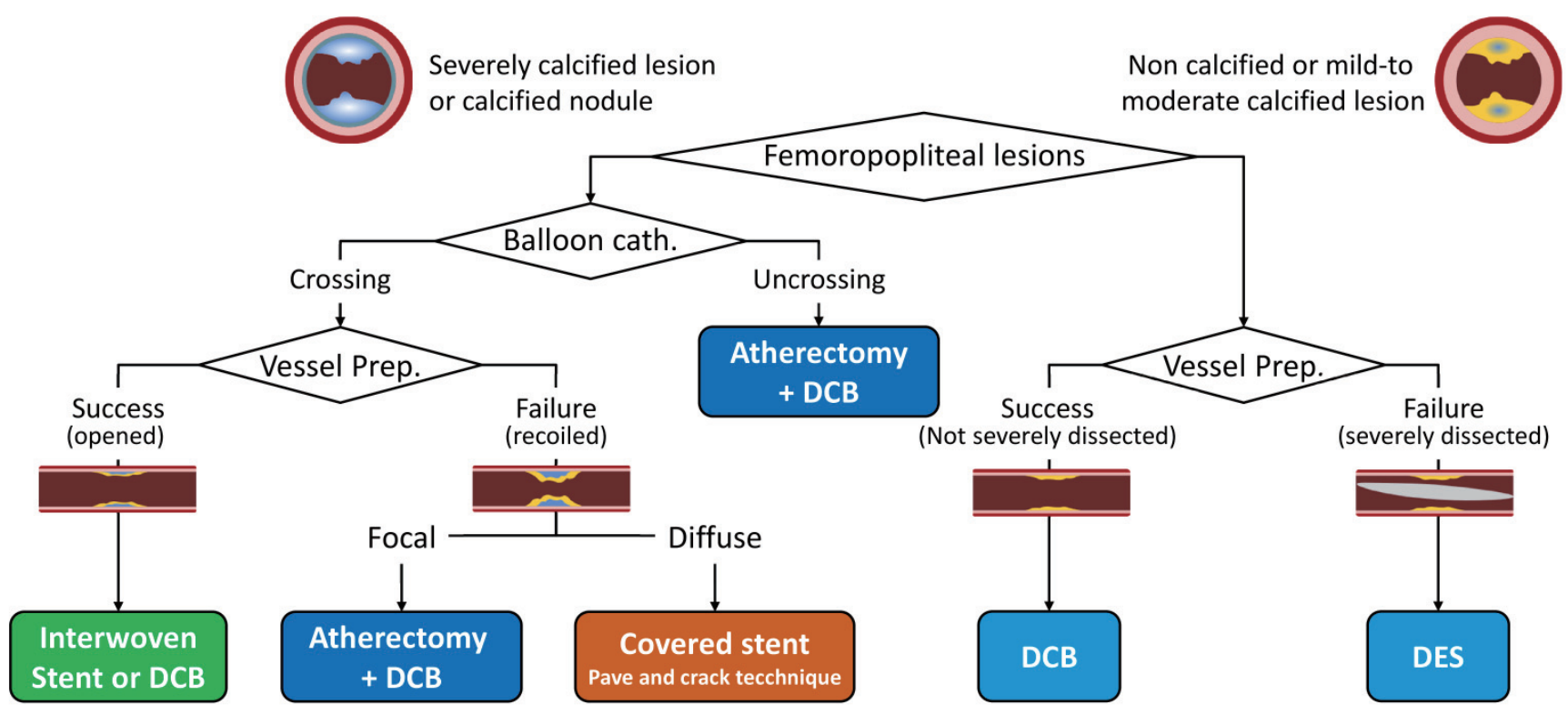

Fig. 1. Treatment algorithm for femoropopliteal lesions

DCB: drug-coated balloon, DES: drug-eluting stent

surgical therapy should be considered for aortic occlusion extending up to renal arteries (class IIa and level C recommendations), whereas hybrid therapy combining iliac stenting and femoral endarterectomy or bypass should be considered for iliofemoral occlusive lesions (class IIa and level C recommendations) ${ }^{17)}$. As for endovascular techniques in the treatment of aortoiliac lesions, primary stenting strategy is generally recommended over provisional stenting strategy. There are several reports on the results of stent-supported EVT for aortoiliac lesions in Japan ${ }^{51,53)}$. Despite the lower incidence of perioperative complications, the long-term primary patency rate is numerically lower than that after surgical therapy ${ }^{17)}$. Another study reported that the primary patency after aortoiliac stenting was comparable to extra-anatomical aortoiliac bypass therapy, whereas primary assisted patency or secondary patency was comparable to anatomical aortoiliac bypass therapy ${ }^{21)}$. Recently, covered stent has been more widely applied to complex aortoiliac lesions and is expected to improve long-term outcomes ${ }^{54)}$.

\section{Revascularization for Femoropopliteal Lesions}

The ESC/ESVS 2017 guidelines and GVG 2019 also stated that surgical bypass therapy using autologous veins is the first-line treatment for complex femoropopliteal lesions (class I and level A recommendations ${ }^{17,21)}$, whereas the definition of "complex lesion" has been repeatedly modified because of the improvement of the technical and long-term success of EVT, thanks to the rapid development of endovascular devices ${ }^{17,21,22,49)}$. Selecting an appropriate device during EVT is clinically important because lesion characteristics considerably vary from case to case. Traditionally, lesion length has been the strongest predictor for loss of patency ${ }^{55)}$ if the endovascular approach is selected. However, the latest devices, including drug-coated balloon (DCB), DES, interwoven stent, and stent-graft, could nullify this notion, and the main driving factor for device selection would be the presence or absence of severe calcification $^{48,56-58)}$. Fig. 1 summarizes our treatment algorithm in femoropopliteal lesions. Lesions without severe calcification are generally treated with $\mathrm{DCB}$ or DES. DES is often chosen over DCB when there is severe dissection defined as grade $\mathrm{C}$ or greater after pre-dilatation. On the other hand, lesions with severe calcification defined as peripheral arterial calcium scoring system of grade 3 or 4 or with calcified nodule are generally treated with interwoven stent or stentgraft. After aggressive vessel preparation, the use of an interwoven stent would be considered if lesions are not perforated but successfully opened. Stent-graft should be applied to lesions with unsuccessful vessel preparation, including vessel perforation or early recoil after aggressive vessel preparation. In the future, when peripheral-specific rotational atherectomy is clinically available in Japan, out treatment algorithm will be concomitantly changed ${ }^{59)}$.

\section{Revascularization for BTK Lesions}

Revascularization for BTK lesions is strictly 
limited to patients with CLTI. The anatomical severity of BTK lesions is stratified by a new classification proposed by the GVG, where the target arterial path is determined by the angiosome concept ${ }^{20)}$. Similar to femoropopliteal lesions, surgical bypass therapy using autologous veins is the gold standard for BTK revascularization, because long-term patency after EVT using plain angioplasty for BTK lesions is extremely dire. BTK lesions are generally complicated with small vessel diameter and severe calcification; plain balloon angioplasty, which is the only device available in Japan, would result in suboptimal outcomes. Current guidelines have recommended selection of endovascular or surgical revascularization in CLTI patients is determined by the presence of usable autologous veins and/or life expectancy ${ }^{17,21)}$. Several studies have recently demonstrated that restenosis rate was reduced by the use of antirestenotic devices, including DCB and DES, in the BTK arteries $^{60,61)}$. These devices will be expected to improve clinical outcomes.

\section{Revascularization for BTA Lesions}

There is a lack of evidence in this area, and although a severity classification has been newly reported in the $\mathrm{GVG}^{17)}$, whether the classification is clinically useful or not has not been fully investigated. To date, severe conditions of BTA lesions have been reported as a negative predictor of clinical outcomes after angioplasty in patients with CLTI ${ }^{62}$. Since the diameter of the vessels ranges from 1.5 to $2.5 \mathrm{~mm}$ and the only one device available is balloon therapy, a high restenosis rate is expected ${ }^{52,63)}$. In this situation, the following aspects remain inconclusive: when interventions should be performed for BTA lesions, how appropriately these lesions are treated by plain angioplasty, and which population should be considered for BTA angioplasty.

\section{Summary}

In this article, we summarize the epidemiology, pharmacology, and EVT of PAD. Evidence in the field of this disease remains insufficient compared with CAD and CVD. We believe that patient outcomes will be improved by risk modification, antithrombotic drug selection, and intervention before referral to a cardiovascular center. In addition, continuing to discuss whether EVT or surgical bypass should be used is necessary. We hope that patient outcomes will improve through the accumulation of new evidence.

\section{Funding Source}

None.

\section{Disclosures}

None.

\section{References}

1) Stoffers HE, Rinkens PE, Kester AD, Kaiser V, Knottnerus JA. The prevalence of asymptomatic and unrecognized peripheral arterial occlusive disease. Int J Epidemiol, 1996; 25: 282-290

2) Hirsch AT, Criqui $M H$, Treat-Jacobson D, Regensteiner JG, Creager MA, Olin JW, Krook SH, Hunninghake DB, Comerota AJ, Walsh ME, McDermott MM, Hiatt WR. Peripheral arterial disease detection, awareness, and treatment in primary care. JAMA, 2001; 286: 1317-1324

3) US Renal Data System 2014 Annual Data Report: Epidemiology of Kidney Disease in the United States. Chapter 10 International comparison. Am J Kidney Dis, 2015; 63: 187-210

4) Boyle JP, Honeycutt AA, Narayan KM, Hoerger TJ, Geiss LS, Chen H, Thompson TJ. Projection of diabetes burden through 2050: impact of changing demography and disease prevalence in the U.S. Diabetes Care, 2001; 24: 1936-1940

5) Rose G, Day S. The population mean predicts the number of deviant individuals. BMJ, 1990; 301: 10311034

6) Fowkes FG, Rudan D, Rudan I, Aboyans V, Denenberg JO, McDermott MM, Norman PE, Sampson UK, Williams LJ, Mensah GA, Criqui MH. Comparison of global estimates of prevalence and risk factors for peripheral artery disease in 2000 and 2010: a systematic review and analysis. Lancet, 2013; 382: 1329-1340

7) Sigvant B, Lundin F, Wahlberg E. The risk of disease progression in peripheral arterial disease is higher than expected: a meta-analysis of mortality and disease progression in peripheral arterial disease. Eur J Vasc Endovasc Surg, 2016; 51: 395-403

8) Ohki T, Yokoi H, Kichikawa K, Kimura T, Snyder SA, Ragheb AO, O'Leary EE, Jaff MR, Ansel GM, Dake MD. Two-year analysis of the Japanese cohort from the Zilver PTX randomized controlled trial supports the validity of multinational clinical trials. J Endovasc Ther, 2014; 21: 644-653

9) Iida O, Takahara M, Soga Y, Kodama A, Terashi H, Azuma N; SPINACH Investigators. Three-Year Outcomes of Surgical Versus Endovascular Revascularization for Critical Limb Ischemia: The SPINACH Study (Surgical Reconstruction Versus Peripheral Intervention in Patients With Critical Limb Ischemia). Circ Cardiovasc Interv, 2017; 10. pii: e005531

10) Bisdas T, Borowski M, Stavroulakis K, Torsello G; CRITISCH Collaborators. Endovascular Therapy Versus Bypass Surgery as First-Line Treatment Strategies for CriticalLimb Ischemia: Results of the Interim Analysis of the CRITISCH Registry. JACC Cardiovasc Interv, 2016; 
9: $2557-2565$

11) Conte MS, Bandyk DF, Clowes AW, Moneta GL, Seely L, Lorenz TJ, Namini H, Hamdan AD, Roddy SP, Belkin M, Berceli SA, DeMasi RJ, Samson RH, Berman SS; PREVENT III Investigators. Results of PREVENT III: a multicenter, randomized trial of edifoligide for the prevention of vein graft failure in lower extremity bypass surgery. J Vasc Surg, 2006; 43: 742-751

12) Iida $O$, Nakamura $M$, Yamauchi $Y$, Fukunaga M, Yokoi $Y$, Yokoi H, Soga Y, Zen K, Suematsu N, Inoue N, Suzuki K, Hirano K, Shintani Y, Miyashita Y, Urasawa K, Kitano I, Tsuchiya T, Kawamoto K, Yamaoka T, Uesugi M, Shinke T, Oba Y, Ohura N, Uematsu M, Takahara M, Hamasaki T, Nanto S; OLIVE Investigators. 3-Year Outcomes of the OLIVE Registry, a Prospective Multicenter Study of Patients With Critical Limb Ischemia: A Prospective, Multi-Center, Three-Year Follow-Up Study on Endovascular Treatment for Infra-Inguinal Vessel in Patients With Critical Limb Ischemia. JACC Cardiovasc Interv, 2015; 8: 1493-1502

13) Adam DJ, Beard JD, Cleveland T, Bell J, Bradbury AW, Forbes JF, Fowkes FG, Gillepsie I, Ruckley CV, Raab G, Storkey H; BASIL trial participants. Bypass versus Angioplasty in Severe Ischemia of the Leg (BASIL): multicenter, randomized controlled trial. Lancet, 2005; 366: 1925-1934

14) Brass EP, Anthony R, Dormandy J, Hiatt WR, Jiao J, Nakanishi A, McNamara T, Nehler M; Circulase investigators. Parenteral therapy with lipo-ecraprost, a lipid-based formulation of a PGE1 analog, does not alter six-month outcomes in patients with critical leg ischemia. J Vasc Surg, 2006; 43: 752-759

15) Watanabe $Y$, Yamagata K, Nishi S, Hirakata H, Hanafusa N, Saito C, Hattori M, Itami N, Komatsu Y, Kawaguchi Y, Tsuruya K, Tsubakihara Y, Suzuki K, Sakai K, Kawanishi $\mathrm{H}$, Inaguma D, Yamamoto $\mathrm{H}$, Takemoto $\mathrm{Y}$, Mori N, Okada K, Hataya H, Akiba T, Iseki K, Tomo T, Masakane I, Akizawa T, Minakuchi J; "Hemodialysis Initiation for Maintenance Hemodialysis" Guideline Working Group, Japanese Society for Dialysis Therapy. Japanese society for dialysis therapy clinical guideline for "hemodialysis initiation for maintenance hemodialysis". Ther Apher Dial, 2015; 19: 93-107

16) Diehm N, Shang A, Silvestro A, Do DD, Dick F, Schmidli J, Mahler F, Baumgartner I. Association of cardiovascular risk factors with pattern of lower limb atherosclerosis in 2659patients undergoing angioplasty. Eur J Vasc Endovasc Surg, 2006; 31: 59-63

17) Aboyans V, Ricco JB, Bartelink MEL, Björck M, Brodmann M, Cohnert T, Collet JP, Czerny M, De Carlo M, Debus S, Espinola-Klein C, Kahan T, Kownator S, Mazzolai L, Naylor AR, Roffi M, Röther J, Sprynger M, Tendera M, Tepe G, Venermo M, Vlachopoulos C, Desormais I; ESC Scientific Document Group. 2017 ESC Guidelines on the Diagnosis and Treatment of Peripheral Arterial Diseases, in collaboration with the European Society for Vascular Surgery (ESVS): Document covering atherosclerotic disease of extracranial carotid and vertebral, mesenteric, renal, upper and lower extremity arteriesEndorsed by: the European Stroke Organization (ESO)The Task Force for the Diagnosis and Treatment of
Peripheral Arterial Diseases of the European Society of Cardiology (ESC) and of the European Society for Vascular Surgery (ESVS). Eur Heart J, 2018; 39: 763-816

18) Ishihara T, Iida O, Tosaka A, Soga Y, Sakamoto Y, Hirano K, Nanto S, UematsuM. Severity of coronary artery disease affects prognosis of patients with peripheral artery disease. Angiology, 2013; 64: 417-422

19) Sianos G, Morel MA, Kappetein AP, Morice MC, Colombo A, Dawkins K, van den Brand M, Van Dyck N, Russell ME, Mohr FW, Serruys PW. The SYNTAX Score: an angiographic tool grading the complexity of coronary artery disease. EuroIntervention, 2005; 1: 219-227

20) Tsujimura T, Iida $O$, Ishihara T, Fujita $M$, Masuda $M$, Okamoto S, Nanto K, Kanda T, Sunaga A, Takahara M, Uematsu M. The impact of coronary artery disease and left ventricular ejection fraction on the prognosis of patients with peripheral artery disease. Intern Med J, 2017; 47: 1313-1316

21) Conte MS, Bradbury AW, Kolh P, White JV, Dick F, Fitridge R, Mills JL, Ricco JB, Suresh KR, Murad MH; GVG Writing Group. Global vascular guidelines on the management of chronic limb-threatening ischemia. Global vascular guidelines on the management of chronic limb-threatening ischemia. J Vasc Surg, 2019; 69: $3 S-125 S$

22) Norgren L, Hiatt WR, Dormandy JA, Nehler MR, Harris KA, Fowkes FG; TASC II Working Group. Inter-Society Consensus for the Management of Peripheral Arterial Disease (TASC II). J Vasc Surg, 2007; 43: S1-67

23) Takahara M, Iida O, Soga Y, Kodama A, Azuma N; SPINACH study investigators. Absence of Preceding Intermittent Claudication and its Associated Clinical Freatures in Patients with Critical Limb Ischemia. J Atheroscler Thromb, 2015; 22: 718-725

24) Takahara M, Iida O, Soga $Y$, Kodama $A$, Terashi $H$, Utsunomiya M, Okazaki J, Azuma N, The Spinach Study Investigators. Duration from Wound Occurrence to Referral to a Vascular Center in Japanese Patients with Critical Limb Ischemia. Ann Vasc Dis, 2020; 13: 56-62

25) CCORD Study Group, Cushman WC, Evans GW, Byington RP, Goff DC Jr, Grimm RH Jr, Cutler JA, Simons-Morton DG, Basile JN, Corson MA, Probstfield JL, Katz L, Peterson KA, Friedewald WT, Buse JB, Bigger JT, Gerstein HC, Ismail-Beigi F. Effects of intensive blood-pressure control in type 2 diabetes mellitus. $\mathrm{N}$ Engl J Med, 2010; 362: 1575-1585

26) Bavry AA, Anderson RD, Gong Y, Denardo SJ, CooperDehoff RM, Handberg EM, Pepine CJ. Outcomes among hypertensive patients with concomitant peripheral and coronary artery disease: findings from the INternational VErapamil- SR/Trandolapril STudy. Hypertension, 2010; 55: $48-53$

27) SPRINT Research Group, Wright JT Jr, Williamson JD, Whelton PK, Snyder JK, Sink KM, Rocco MV, Reboussin DM, Rahman M, Oparil S, Lewis CE, Kimmel PL, Johnson KC, Goff DC Jr, Fine LJ, Cutler JA, Cushman WC, Cheung AK, Ambrosius WT. A randomized trial of intensive 3versus standard blood-pressure control. N Engl J Med, 2015; 373: 2103-2116

28) Moise N, Huang C, Rodgers A, Kohli-Lynch CN, Tzong KY, Coxson PG, Bibbins-Domingo K, Goldman L, 
Moran AE. Comparative cost-effectiveness of conservative or intensive blood pressure treatment guidelines in adults aged 35-74 years: the Cardiovascular Disease Policy Model. Hypertension, 2016; 68: 88-96

29) Mach F, Baigent C, Catapano AL, Koskinas KC, Casula M, Badimon L, Chapman MJ, De Backer GG, Delgado V, Ference BA, Graham IM, Halliday A, Landmesser U, Mihaylova B, Pedersen TR, Riccardi G, Richter DJ, Sabatine MS, Taskinen MR, Tokgozoglu L, Wiklund O; ESC Scientific Document Group. 2019 ESC/EAS Guidelines for the management of dyslipidaemias: lipid modification to reduce cardiovascular risk. Eur Heart J, 2020; 41: 111-188

30) Selvin E, Marinopoulos S, Berkenblit G, Rami T, Brancati FL, Powe NR, Golden SH. Meta-analysis: glycosylated hemoglobin and cardiovascular disease in diabetes mellitus. Ann Intern Med, 2004; 141: 421-431

31) Nathan DM, Cleary PA, Backlund JY, Genuth SM, Lachin JM, Orchard TJ, Raskin P, Zinman B; Diabetes Control and Complications Trial/Epidemiology of Diabetes Interventions and Complications (DCCT/ EDIC) Study Research Group. Intensive diabetes treatment and cardiovascular disease in patients with type 1 diabetes. N Engl J Med, 2005; 353: 2643-2653

32) van Dieren $S$, Kengne AP, Chalmers J, Beulens JW, Davis TM, Fulcher G, Heller SR, Patel A, Colagiuri S, Hamet P, Mancia G, Marre M, Neal B, Williams B, Peelen LM, van der Schouw YT, Woodward M, Zoungas S. Intensification of medication and glycaemic control among patients with type 2 diabetesdthe ADVANCE trial. Diabetes Obes Metab, 2014; 16: 426-432

33) Fox CS, Golden SH, Anderson C, Bray GA, Burke LE, de Boer IH, Deedwania P, Eckel RH, Ershow AG, Fradkin J, Inzucchi SE, Kosiborod M, Nelson RG, Patel MJ, Pignone M, Quinn L, Schauer PR, Selvin E, Vafiadis DK; American Heart Association Diabetes Committee of the Council on Lifestyle and Cardiometabolic Health; Council on Clinical Cardiology, Council on Cardiovascular and Stroke Nursing, Council on Cardiovascular Surgery and Anesthesia, Council on Quality of Care and Outcomes Research; American Diabetes Association. Update on Prevention of Cardiovascular Disease in Adults With Type 2 Diabetes Mellitus in Light of Recent Evidence: A Scientific Statement From the American Heart Association and the American Diabetes Association. Diabetes Care, 2015; 38 : 1777-1803

34) American Diabetes Association. 6. Glycemic Targets: Standards of Medical Care in Diabetesd2018. Diabetes Care, 2018; 41(Suppl 1): S55-64

35) CAPRIE Steering Committee. A randomised, blinded, trial of clopidogrelversus aspirin in patients at risk of ischaemic events (CAPRIE). CAPRIE. Steering Committee. Lancet, 1996; 348: 1329-1339

36) Strobl FF, Brechtel K, Schmehl J, Zeller T, Reiser MF, Claussen CD, Tepe G. Twelve-month results of a randomized trial comparing mono with dual antiplatelet therapy in endovascularly treated patients with peripheral artery disease. J Endovasc Ther, 2013; 20: 699-706

37) Belch JJ, Dormandy J; CASPAR Writing Committee, Biasi GM, Cairols M, Diehm C, Eikelboom B, Golledge
J, Jawien A, Lepäntalo M, Norgren L, Hiatt WR, Becquemin JP, Bergqvist D, Clement D, Baumgartner I, Minar E, Stonebridge P, Vermassen F, Matyas L, Leizorovicz A. Results of the randomized, placebocontrolled clopidogrel and acetylsalicylic acid in bypass surgery for peripheral arterial disease (CASPAR) trial. J Vasc Surg, 2010; 52: 825-833

38) Pande RL, Perlstein TS, Beckman JA, Creager MA. Secondary prevention and mortality in peripheral artery disease: National Health and Nutrition Examination Study, 1999 to 2004. Circulation, 2011; 124: 17-23

39) Schramm K, Rochon PJ. Gender Differences in Peripheral Vascular Disease. Semin Intervent Radiol, 2018; 35: 9-16

40) Belch J, MacCuish A, Campbell I, Cobbe S, Taylor R, Prescott R, Lee R, Bancroft J, MacEwan S, Shepherd J, Macfarlane P, Morris A, Jung R, Kelly C, Connacher A, Peden N, Jamieson A, Matthews D, Leese G, McKnight J, O'Brien I, Semple C, Petrie J, Gordon D, Pringle S, MacWalter R; Prevention of Progression of Arterial Disease and Diabetes Study Group; Diabetes Registry Group; Royal College of Physicians Edinburgh. The prevention of progression of arterial disease and diabetes (POPADAD) trial: factorial randomised placebo controlled trial of aspirin and antioxidants in patients with diabetes and asymptomatic peripheral arterial disease. BMJ, 2008; 337: a1840

41) Fowkes FG, Price JF, Stewart MC, Butcher I, Leng GC, Pell AC, Sandercock PA, Fox KA, Lowe GD, Murray GD; Aspirin for Asymptomatic Atherosclerosis Trialists. Aspirin for prevention of cardiovascular events in a general population screened for a low ankle brachial index: a randomized controlled trial. JAMA, 2010; 303: 841-848

42) Antithrombotic Trialists Collaboration. Collaborative meta-analysis of randomized trials of antiplatelet therapy for prevention of death, myocardial infarction, and stroke in high risk patients. BMJ, 2002; 324: 71-86

43) Cacoub PP, Bhatt DL, Steg PG, Topol EJ, Creager MA; CHARISMA Investigators. Patients with peripheral arterial disease in the CHARISMA trial. Eur Heart J, 2009; 30: 192-201

44) Armstrong EJ, Anderson DR, Yeo KK, Singh GD, Bang H, Amsterdam EA,vFreischlag JA, Laird JR. Association of dual-antiplatelet therapy with reducedvmajor adverse cardiovascular events in patients with symptomatic peripheralvarterial disease. J Vasc Surg, 2015; 62: 157 165

45) Gray WA, Keirse K, Soga Y, Benko A, Babaev A, Yokoi Y, Schroeder H, Prem JT, Holden A, Popma J, Jaff MR, Diaz-Cartelle J, Müller-Hülsbeck S; IMPERIAL investigators. A polymer-coated, paclitaxel-eluting stent (Eluvia) versus a polymer-free, paclitaxel-coated stent (Zilver PTX) for endovascular femoropopliteal intervention (IMPERIAL): a randomised, non-inferiority trial. Lancet, 2018; 392: 1541-1551

46) Bonaca MP, Bauersachs RM, Anand SS, Debus ES, Nehler MR, Patel MR, Fanelli F, Capell WH, Diao L, Jaeger N, Hess CN, Pap AF, Kittelson JM, Gudz I, Mátyás L, Krievins DK, Diaz R, Brodmann M, Muehlhofer E, Haskell LP, Berkowitz SD, Hiatt WR. Rivaroxaban in Peripheral Artery Disease after 
Revascularization. N Engl J Med, 2020; 382: 1994-2004

47) Iida O, Takahara M, Soga $Y$, Yamaoka T, Nanto S, Kuratani T, Sakata Y, Mano T. One-Year Outcomes of Heparin-Bonded Stent-Graft Therapy for Real-World Femoropopliteal Lesions and the Association of Patency With the Prothrombotic State Based on the Prospective, Observational, Multicenter ViabahnStent-Graft Placement for Femoropopliteal Diseases Requiring Endovascular Therapy (VANQUISH) Study. J Endovasc Ther, 2021; 28: 123-131

48) Fukunaga M, Kawasaki D, Nishimura M, Yamagami M, Fujiwara R, Nakata T. Clinical Effects of Planned Endovascular Therapy for Critical Limb Ischemia Patients with Tissue Loss. J Atheroscler Thromb, 2019; 26: 294301

49) Dormandy JA, Rutherford RB. Management of peripheral arterial disease (PAD). TASC Working Group. TransAtlantic Inter-Society Consensus (TASC). J Vasc Surg, 2000; 31: S1-S296

50) Yamauchi Y, Takahara M, Shintani Y, Iida O, Sugano T, Yamamoto Y, Kawasaki D, Fujihara M, Hirano K, Yokoi H, Miyamoto A, Nakamura M; OMOTENASHI investigators. One-Year Outcomes of Endovascular Therapy for Aortoiliac Lesions. Circ Cardiovasc Interv, 2019; 12: e007441. doi: 10.1161/CIRCINTERVENTIONS.118.007441

51) Iida O, Takahara M, Soga Y, Fujihara M, Kawasaki D, Hirano K, Choi D, Mano T. A Novel Angiographic Risk Score for Femoropopliteal Interventions. J Endovasc Ther, 2020; 27: 967-973

52) Hata Y, Iida O, Takahara M, Asai M, Masuda M, Okamoto S, Ishihara T, Nanto K, Kanda T, Tsujimura T, Okuno S, Matsuda Y, Mano T. Infrapopliteal Anatomic Severity and Delayed Wound Healing in Patients With Chronic Limb-Threatening Ischemia in the Era of the Global Limb Anatomic Staging System. J Endovasc Ther, 2020; 27: 641-646

53) Soga Y, Iida O, Kawasaki D, Yamauchi Y, Suzuki K, Hirano K, Koshida R, Kamoi D, Tazaki J, Higashitani M, Shintani Y, Yamaoka T, Okazaki S, Suematsu N, Tsuchiya T, Miyashita Y, Shinozaki N, Takahashi H; REAL-AI investigators. Contemporary outcomes after endovascular treatment for aorto-iliac artery disease. Circ J, 2012; 76 : 2697-2704

54) Feldman DN, Armstrong EJ, Aronow HD, Banerjee S, Díaz-Sandoval LJ, Jaff MR, Jayasuriya S, Khan SU, Klein AJ, Parikh SA, Rosenfield K, Shishehbor MH, Swaminathan RV, White CJ. SCAI guidelines on device selection in Aorto-Iliac arterial interventions. Catheter Cardiovasc Interv, 2020; 96: 915-929

55) Soga Y, Iida O, Hirano K, Suzuki K, Tosaka A, Yokoi H, Nobuyoshi M. Utility of new classification based on clinical and lesional factors after self-expandable nitinol stenting in the superficial femoral artery. J Vasc Surg, 2011; 54: 1058-1066

56) Schneider PA, Laird JR, Tepe G, Brodmann M, Zeller T, Scheinert D, Metzger C, Micari A, Sachar R, Jaff MR, Wang H, Hasenbank MS, Krishnan P; IN.PACT SFA Trial Investigators. Treatment Effect of Drug-Coated Balloons Is Durable to 3 Years in the Femoropopliteal Arteries: Long-Term Results of the IN.PACT SFA Randomized Trial. Circ Cardiovasc Interv, 2018; 11: e005891

57) Gray WA, Keirse K, Soga Y, Benko A, Babaev A, Yokoi Y, Schroeder H, Prem JT, Holden A, Popma J, Jaff MR, Diaz-Cartelle J, Müller-Hülsbeck S; IMPERIAL investigators. A polymer-coated, paclitaxel-eluting stent (Eluvia) versus a polymer-free, paclitaxel-coated stent (Zilver PTX) for endovascular femoropopliteal intervention (IMPERIAL): a randomised, non-inferiority trial. Lancet, 2018; 392: 1541-1551

58) Iida O, Takahara M, Soga Y, Hirano K, Yamauchi Y, Zen K, Kawasaki D, Nanto S, Yokoi H, Uematsu M; ZEPHYR Investigators. The characteristics of in-stent restenosis after drug-eluting stent implantation in femoropopliteal lesions and 12-month prognosis after repeat endovascular therapy for these lesions. JACC Cardiovasc Interv, 2016; 9: 828-834

59) Shammas NW. JETSTREAM Atherectomy: A Review of Technique, Tips, and Tricks in Treating the Femoropopliteal Lesions. Int J Angiol, 2015; 24: 81-86

60) Bosiers M, Scheinert D, Peeters P, Torsello G, Zeller T, Deloose K, Schmidt A, Tessarek J, Vinck E, Schwartz LB. Randomized comparison of everolimus-eluting versus bare-metal stents in patients with critical limb ischemia and infrapopliteal arterial occlusive disease. J Vasc Surg, 2012; 55: 390-398

61) Cassese S, Ndrepepa G, Liistro F, Fanelli F, Kufner S, Ott I, Laugwitz KL, Schunkert H, Kastrati A, Fusaro M. Drug-Coated Balloons for Revascularization of Infrapopliteal Arteries: A Meta-Analysis of Randomized Trials. JACC Cardiovasc Interv, 2016 23; 9: 1072-1080

62) Iida O, Soga Y, Yamauchi Y, Hirano K, Kawasaki D, Yamaoka T, Takahara M, Uematsu M. Clinical efficacy of endovascular therapy for patients with critical limb ischemia attributable to pure isolated infrapopliteal lesions. J Vasc Surg, 2013; 57: 974-981

63) Iida O, Soga Y, Kawasaki D, Hirano K, Yamaoka T, Suzuki K, Miyashita Y, Yokoi H, Takahara M, Uematsu M. Angiographic restenosis and its clinical impact after infrapopliteal angioplasty. Eur J Vasc Endovasc Surg, 2012; 44: 425-431 